Article

\title{
Study on the Corrosion Fatigue Properties of 12Cr1MoV Steel at High Temperature in Different Salt Environments
}

\author{
Jianjun He, Jiangyong Bao, Kailiang Long, Cong Li * and Gang Wang \\ School of Energy and Power Engineering, Changsha University of Science and Technology, \\ Changsha 410114, China \\ * Correspondence: liconghntu@csust.edu.cn; Tel.: +86-0731-85258409
}

Received: 6 June 2019; Accepted: 7 July 2019; Published: 10 July 2019

check for updates

\begin{abstract}
Biomass energy, as a reliable renewable energy source, has gained more and more attention. However, microstructure degradation and corrosion fatigue damage of heat pipes hinder its further application. In this paper, high temperature corrosion fatigue characteristics of $12 \mathrm{Cr} 1 \mathrm{MoV}$ steel under a mixed alkali metal chloride salt environment and mixed sulfate salt environment were investigated. Fatigue tests with different total strain amplitudes were performed. Results show that the effect of total strain amplitude on the cyclic stress response of the alloy is approximately the same under three different deformation conditions. With the increase of the cyclic numbers, the alloyed steel mainly exhibited cyclic hardening during loading. The fatigue properties in air environment were the best, which is most obvious when the total strain amplitude is $\pm 0.3 \%$. The fatigue life of samples in mixed alkali metal salts is the shortest. Furthermore, the fatigue fracture morphology of the alloyed steel in different environments were also deeply analyzed. This experimental study attempts to provide a theoretical reference for solving the problem of rapid failure of heat pipes in biomass boilers, and to establish a scientific basis for the material selection and safety operation.
\end{abstract}

Keywords: high temperature; $12 \mathrm{Cr} 1 \mathrm{MoV}$ steel; mixed salt environments; corrosion fatigue; heat pipe failure

\section{Introduction}

As a kind of renewable energy, biomass energy has attracted considerable attention in recent years due to its rich resources and lower pollution. However, most of the biomass fuels generally contain a large number of alkali metals, alkaline earth metals, sulfides, and chlorine elements with high concentration [1]. Alkali metal chlorides and sulfides are the main compounds produced during biomass combustion. They generally exist in the form of $\mathrm{KCl}, \mathrm{NaCl}, \mathrm{K}_{2} \mathrm{SO}_{4}$, and $\mathrm{Na}_{2} \mathrm{SO}_{4}$. Alkali metal compounds in fuels tend to flow with flue gas at high temperatures, then deposit on the wall of the superheater, and form alkali metal salt slagging with complex composition [2]. This phenomenon easily leads to local overheating, which makes the high temperature salt exist in a liquid pool state. On the other hand, when biomass burns, the sulfur content will be released. Part of the released sulfur is combined with oxygen to form $\mathrm{SO}_{2}$ gas, which is mixed with flue gas and discharged outside of the boiler The other part will deposit in the form of sulfate onto the inside of the boiler. These sulfates will react with the oxide film on the metal surface at high temperatures, which results in corrosion. At the same time, because the heat pipe of the boiler superheater works in high temperature environments [3], the components need to bear more complex loading, which will lead to a local stress concentration, thus resulting in a local plastic deformation and fatigue damage of the material [4]. With the accumulation of deformation, defect structures and cracks are formed [5]. Cracks propagate unstably under the 
combined action of a hot corrosion environment [6] and high temperature fatigue [7], which leads to bursting and failure of the steel tube.

The molten salt corrosion is a complex process, involving chemical corrosion, electrochemical corrosion, as well as the interface reaction and the dissolution of oxides. The corrosion resistance at high temperatures is largely dependent on the formation of protective oxidation layer. $\mathrm{Cl}$-Cl-containing environments are well known to cause accelerated corrosion, resulting in increased oxidation, metal wastage, void formation, and loose non-adherent scales, hence destroying the protective oxidation layers [8]. During the fatigue process, corrosion caused by alkali chloride and sulfate salt is one of the most important factors that determine the service life of the heat pipe. In terms of research on the corrosion fatigue of alloys in a salt environment, the following papers are listed. Liu et al. found that the $\mathrm{NaCl}-\mathrm{KCl}$ mixture could accelerate the corrosion process of TP347H stainless steel and $\mathrm{C} 22$ alloy in molten chloride [9]. Zhang et al. have reported that Ni-20Cr-18W alloy suffered severe thermal corrosion in mixed molten salt, the main corrosion products are almost the same at different temperatures [10]. Tsaur et al. used a 310 stainless steel with pre-coated $\mathrm{NaCl}-\mathrm{Na}_{2} \mathrm{SO}_{4}$ mixture for hot corrosion tests. The experiments have proved that $\mathrm{NaCl}$ is the main corrosion catalyst at high temperature. The presence of the $\mathrm{NaCl}$ in deposits inhibits the formation of protective oxidation layers at the initial stage, leading to an acceleration of hot corrosion of 310 stainless steel [11].

However, to our best knowledge, until now most experimental research on corrosion fatigue has been carried out mainly from the aspects of salt corrosion, solution corrosion, and so on. In fact, the actual operating environment of the biomass boiler superheater heat pipe is very complex. In many cases, thermal corrosion and fatigue damage caused by biomass combustion will act on the heat pipe material simultaneously, thus accelerating the degradation and failure of the material. Therefore, it is of great significance to study corrosion fatigue characteristics of the heat pipe materials for biomass boilers from the perspective of an interaction between corrosion and fatigue. As a kind of high strength alloyed steel, $12 \mathrm{Cr} 1 \mathrm{MoV}$ steel possesses excellent corrosion resistance and mechanical properties. It is widely used in coal-fired boilers and biomass boiler heat pipes at temperatures below $600{ }^{\circ} \mathrm{C}$. In this study, $12 \mathrm{Cr} 1 \mathrm{MoV}$ steel was chosen as the research material, and corrosion fatigue characteristics of $12 \mathrm{Cr} 1 \mathrm{MoV}$ steel at a high temperature under different loading conditions and chemical environments were deeply investigated.

\section{Materials and Methods}

The experimental material used in this study was $12 \mathrm{Cr} 1 \mathrm{MoV}$ rolled round steel with a diameter of $20 \mathrm{~mm}$. The chemical composition is shown in Table 1.

Table 1. Chemical composition of $12 \mathrm{Cr} 1 \mathrm{MoV}$ steel (wt $\%)$.

\begin{tabular}{cccccccc}
\hline Element & $\mathbf{C}$ & $\mathbf{C r}$ & $\mathbf{M n}$ & $\mathbf{M o}$ & $\mathbf{S i}$ & $\mathbf{V}$ & $\mathbf{F e}$ \\
\hline Content & 0.1 & 1.03 & 0.54 & 0.3 & 0.24 & 0.2 & Balance \\
\hline
\end{tabular}

In this paper, fatigue tests of alloyed steel were carried out under three different environments: an air environment (reference test), a mixed alkali metal salt environment, and a mixed sulfate environment. The alkali metal salts used in this experiment are $\mathrm{KCl}$ and $\mathrm{NaCl}$, which are mixed according to the mass ratio of $70 \% \mathrm{NaCl}+30 \% \mathrm{KCl}$ (mixed chloride salt). The composition of mixed sulfates is $70 \% \mathrm{Na}_{2} \mathrm{SO}_{4}+30 \% \mathrm{~K}_{2} \mathrm{SO}_{4}$. Most biomass boilers set their rated steam temperatures at $450{ }^{\circ} \mathrm{C}, 540{ }^{\circ} \mathrm{C}$, and $580^{\circ} \mathrm{C}$. Considering that there is a heat storage process on the surface of the steam pipe when the boiler is in operation, the temperature of the heat pipe surface is actually higher than that of the rated steam temperature, therefore in our experiments, the temperature was set to be $600{ }^{\circ} \mathrm{C}$. The total strain amplitudes of each group were selected to be $+0.5 \%,+0.4 \%,+0.3 \%$, and $+0.2 \%$ for low-cycle fatigue tests, the frequency was $0.2 \mathrm{~Hz}$, and the strain rate was $10^{-3} / \mathrm{s}$. Specific experimental schemes are shown in Table 2. 
Table 2. Fatigue experimental scheme of $12 \mathrm{Cr} 1 \mathrm{MoV}$ alloy.

\begin{tabular}{ccccc}
\hline Temperature $\left({ }^{\circ} \mathrm{C}\right)$ & Strain Amplitude & Waveform & Frequency (HZ) & Environment \\
& $\pm 0.4 \%$ & & & Air/Mixed Alkali \\
& $\pm 0.5 \%$ & Cosine wave & 0.2 & metal chloride salt \\
& $\pm 0.3 \%$ & & (Type A)/Mixed \\
& $\pm 0.2 \%$ & & sulfate salt (Type B) \\
\hline
\end{tabular}

The fatigue specimens with a dimension of $40 \mathrm{~mm}$ standard distance, $8 \mathrm{~mm}$ diameter, and M14 threads at both sides were prepared, as shown in Figure 1a. Specimens were polished smoothly with different sandpapers. Before any further experiments, samples were cleaned with alcohol for $15 \mathrm{~min}$ and repeated twice in order to remove impurities and grease on the surface of the samples. The mechanical property tests were conducted on a RDL05 electronic creep-fatigue testing machine. Extensometers and thermocouples were used to measure the strain and temperature respectively. The installation is schematically shown in Figure $1 \mathrm{~b}$. The tensile tests were performed at room temperature and $600{ }^{\circ} \mathrm{C}$ in the air with a strain rate of $10^{-3} \mathrm{~s}^{-1}$. In order to assure the repeatability of the results, each test was performed three times.

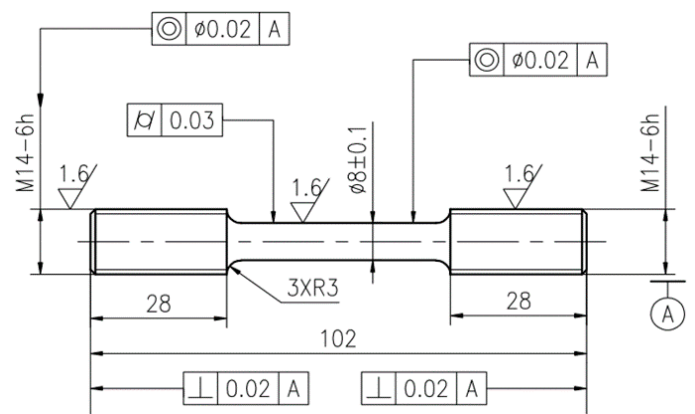

(a)

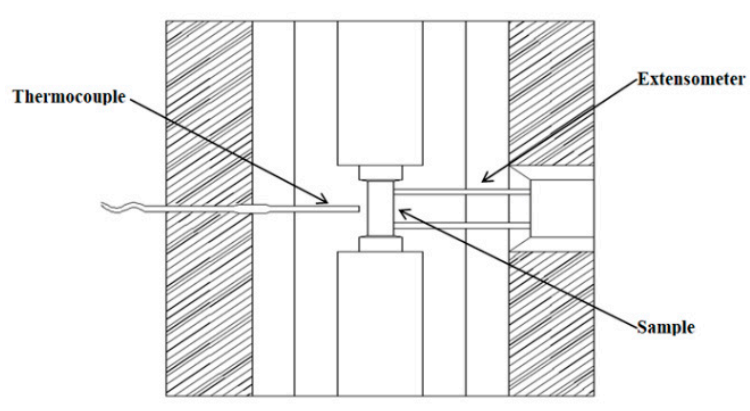

(b)

Figure 1. Experimental sample and device, (a) shape and dimensions of fatigue test specimens (dimensions in $\mathrm{mm}$ ), and (b) installation of extensometers and thermocouples.

Saturated salt solutions were prepared according to the set mass ratio evenly coated on the sample surface using a small brush. In order to volatilize the water, samples were preheated in a furnace at $100^{\circ} \mathrm{C}$. After several minutes, a salt layer of a certain thickness was adhered to the surface of the samples. This process was repeated until a certain thickness of salt layer was uniformly attached. The fracture surfaces of the fatigue samples were observed by Quanta FEG 250 SEM using a voltage of $20 \mathrm{kV}$.

\section{Results and Discussion}

\subsection{Effect of Total Strain Amplitudes}

In order to identify the effect of total strain amplitudes on the fatigue property of $12 \mathrm{Cr} 1 \mathrm{MoV}$ steel, low-cycle fatigue experiments with different total strain amplitudes under a mixed chloride salt environment, a mixed sulfate salt environment, and an air condition were carried out at $600{ }^{\circ} \mathrm{C}$. Figure 2 shows the cyclic stress as a function of cyclic numbers. As seen in Figure 2, the effect of total strain amplitude on the cyclic stress response of the alloy is approximately the same under three different deformation conditions. For all samples, with the increase of total strain amplitude, the cyclic stress values increased and the fatigue life decreased significantly. This is a very normal and reasonable result. On the other hand, with the increase of the cyclic numbers, all of the samples presented an increment of the cyclic stress, especially at the strain amplitudes of $\pm 0.3 \%$ and $\pm 0.2 \%$. Therefore, it can be concluded that the alloyed steel mainly exhibited cyclic hardening during the loading. This phenomenon is consistent with the data calculated from the uni-axial tensile test, as shown in Table 3. Generally, 
cyclic hardening and softening of material can be determined by the data of the uni-axial tensile test. When $\sigma_{\mathrm{b}} / \sigma_{0.2}>1.4$, the material exhibits cyclic hardening; when $\sigma_{\mathrm{b}} / \sigma_{0.2}<1.2$, the material exhibits cyclic softening; and when $1.4>\sigma_{\mathrm{b}} / \sigma_{0.2}>1.2$, it is impossible to determine whether the material is cyclic hardening or cyclic softening [12]. Based on the data of the tensile test at $600{ }^{\circ} \mathrm{C}$, it can be calculated that: $\sigma_{\mathrm{b}} / \sigma_{0.2}=544 / 311=1.749>1.4$. According to the calculation, cyclic hardening should occur during the fatigue test at $600{ }^{\circ} \mathrm{C}$ for the $12 \mathrm{Cr} 1 \mathrm{MoV}$ steel, which is consistent with the curves drawn from the experiments.

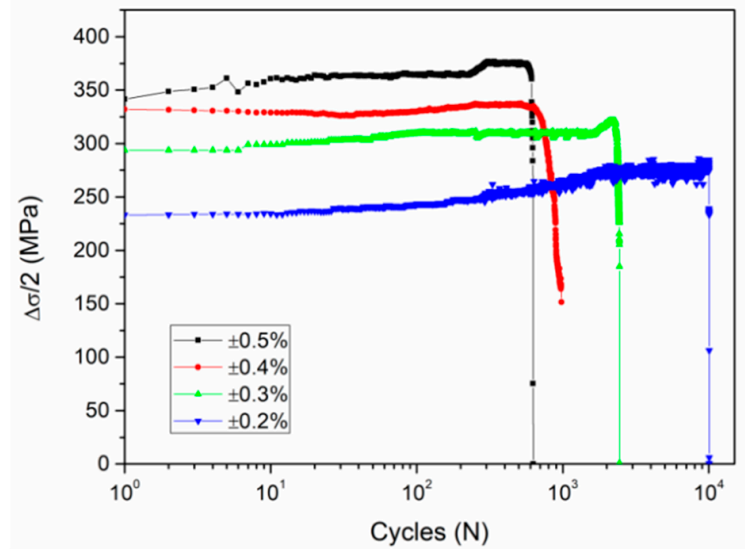

(a)

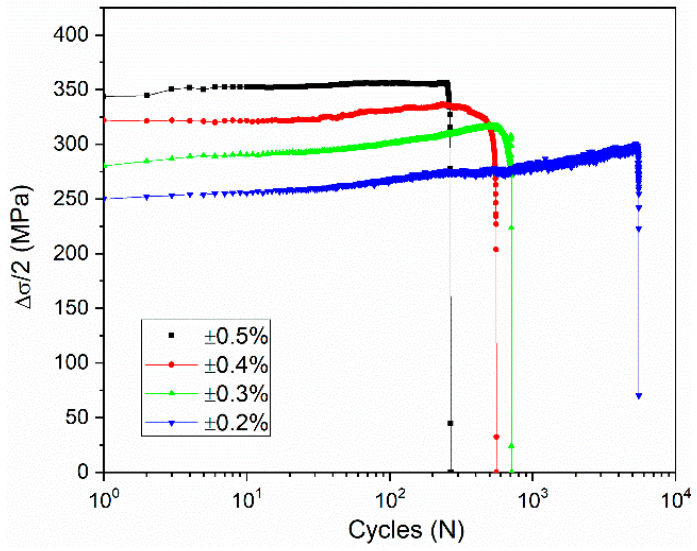

(b)

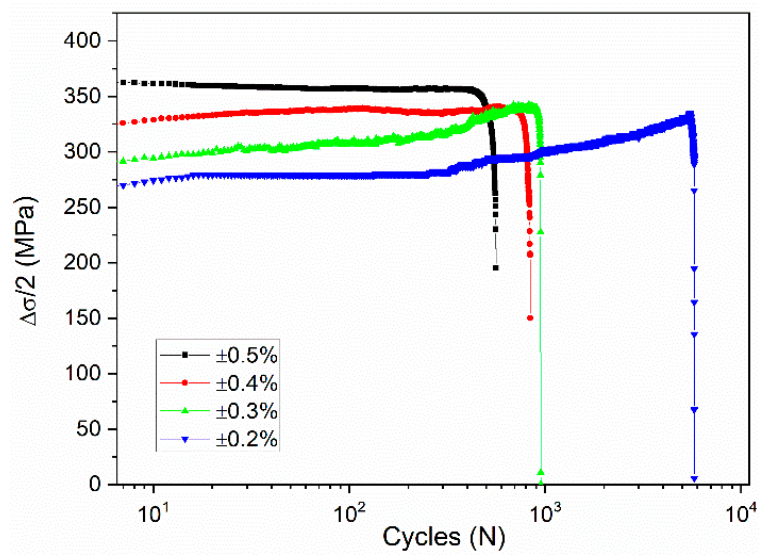

(c)

Figure 2. Cyclic stress response of the steel at $600{ }^{\circ} \mathrm{C}$ (a) air environment, (b) mixed chloride salt environment, and (c) mixed sulfate salt environment.

Table 3. Tensile mechanical properties of $12 \mathrm{Cr} 1 \mathrm{MoV}$ steel.

\begin{tabular}{cccc}
\hline Temperature $\left({ }^{\circ} \mathbf{C}\right)$ & $\boldsymbol{\sigma}_{\mathbf{b}}(\mathbf{M P a})$ & $\left.\boldsymbol{\sigma}_{\mathbf{0 . 2}} \mathbf{( M P a}\right)$ & $\boldsymbol{A}(\boldsymbol{\%})$ \\
\hline Room temperature & $715 \pm 32$ & $521 \pm 24$ & $21.5 \pm 1.1$ \\
600 & $544 \pm 22$ & $311 \pm 17$ & $42.7 \pm 2.3$ \\
\hline
\end{tabular}

The Holomon expression is used to depict the relationship between the magnitude of the stress and the amplitude of the plastic strain [13], as shown in Equation (1):

$$
\frac{\Delta \sigma}{2}=K^{\prime}\left(\frac{\Delta \varepsilon_{\mathrm{p}}}{2}\right)^{n^{\prime}}
$$

where $K^{\prime}$ is the cyclic strength coefficient, and $n^{\prime}$ is the strain hardening exponent. After taking logarithms on both sides, the relationship between the total strain amplitude and stress of the samples 
under different deformation environments was plotted in Figure 3. In this figure, Type A represents mixed alkali metal salt samples, and Type B represents mixed sulfate samples. It can be seen that for all of the samples, the three fitting lines are almost parallel to each other. The $n^{\prime}$ value is the slope of a straight line, and the $K^{\prime}$ value is the intercept of a straight line on the longitudinal axis. It can be concluded the values of the cyclic strength coefficient $K^{\prime}$ and the strain hardening exponent $n^{\prime}$ in the three environments are almost the same. After extensive research on high-strength materials commonly used in industry, Landgra [14] proposed that the strain hardening exponent $n^{\prime}$ can be used to evaluate the effect of cyclic strain on material properties. When $n^{\prime}<0.1$, the material behaves as cyclic softening, when $n^{\prime}>0.1$, the material exhibits cyclic hardening or cycle stability. After fitting, the strain hardening exponent is obtained, as shown in Table 4, with $n_{\text {air }}^{\prime}=0.1083>0.1, n_{\text {mcs }}^{\prime}=0.1102>0.1$, $n_{\mathrm{mss}}^{\prime}=0.1107>0.1$. According to this standard, $12 \mathrm{Cr} 1 \mathrm{MoV}$ steel mainly exhibits cyclic hardening or cycle stability, which is consistent with the results of the monotonic tensile determination and the cyclic stress response determination. In addition, all of the samples show a cyclic softening before the final fracture, with the cyclic stress decreasing rapidly during the last several cycles. The reason is that the fatigue crack becomes unstable and propagates rapidly and fractures eventually after the nucleation and coalescence.

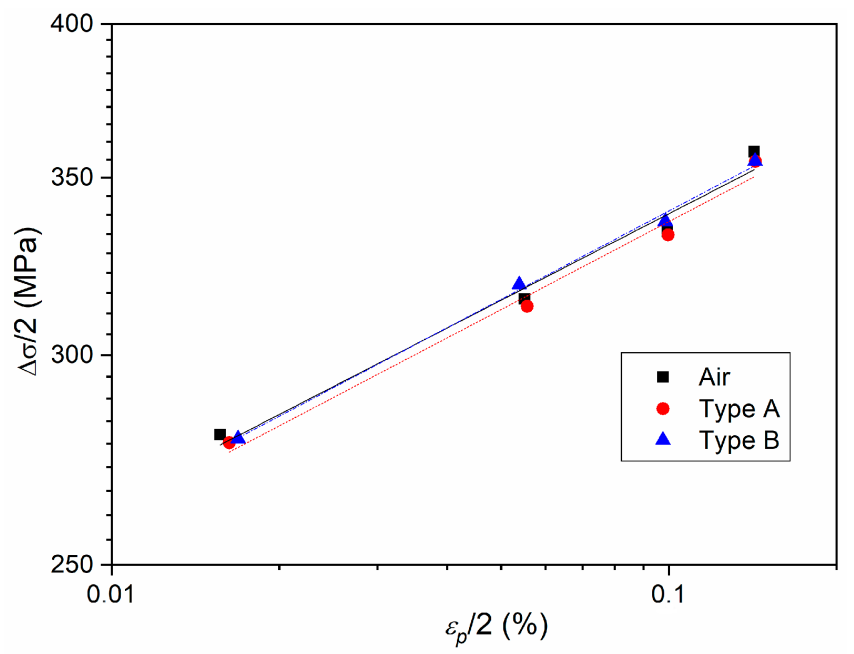

Figure 3. Cyclic stress-strain relationships of samples under different deformation environments.

Table 4. Low-cycle fatigue characteristics parameters $K^{\prime}$ and $n^{\prime}$.

\begin{tabular}{cccc}
\hline Parameter & Air & Mixed Chloride Salt & Mixed Sulfate Salt \\
\hline$K^{\prime}$ & 435 & 434 & 438 \\
$n^{\prime}$ & 0.1083 & 0.1102 & 0.1107 \\
\hline
\end{tabular}

\subsection{Effect of Deformation Environments}

The cyclic stress response of alloyed steel under different loading environments is shown in Figure 4. It can be seen that different deformation environments have a great influence on the mechanical properties of the specimens. Generally speaking, the fatigue properties of samples in the air environment are the best, which is most obvious when the total strain amplitude is $\pm 0.3 \%$. The fatigue life of samples in mixed alkali metal salts is the shortest. The fatigue life (loading cycles) of all samples are listed in Table 5. It can be clearly seen that the differences in fatigue life caused by environments are different under various total strain amplitudes. When the total strain amplitude is $\pm 0.2 \%$, the fatigue life of the alloy under a mixed alkali metal salt environment is almost the same as that under a mixed sulfate environment, but it is lower than that of the sample under an air environment. When the total strain amplitude is $\pm 0.3 \%$, the fatigue life of the samples under the three environments has the greatest 
distinction. When the total strain amplitude is $\pm 0.4 \%$ and $\pm 0.5 \%$, the effect of mixed sulfate on the fatigue properties of samples is very limited.

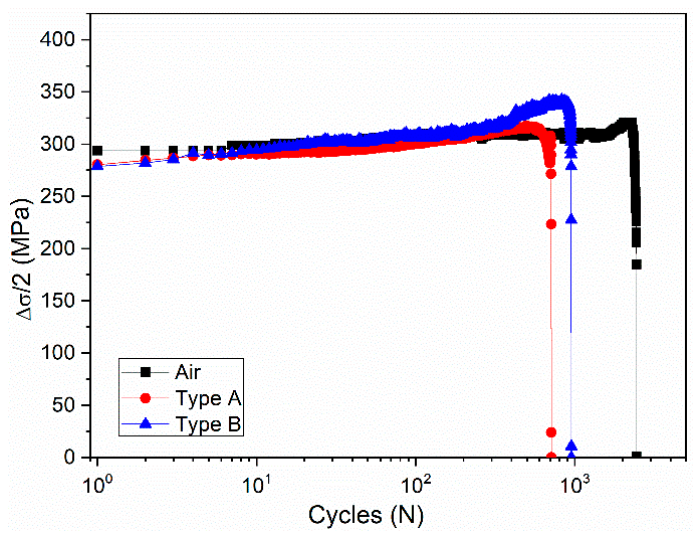

(a)

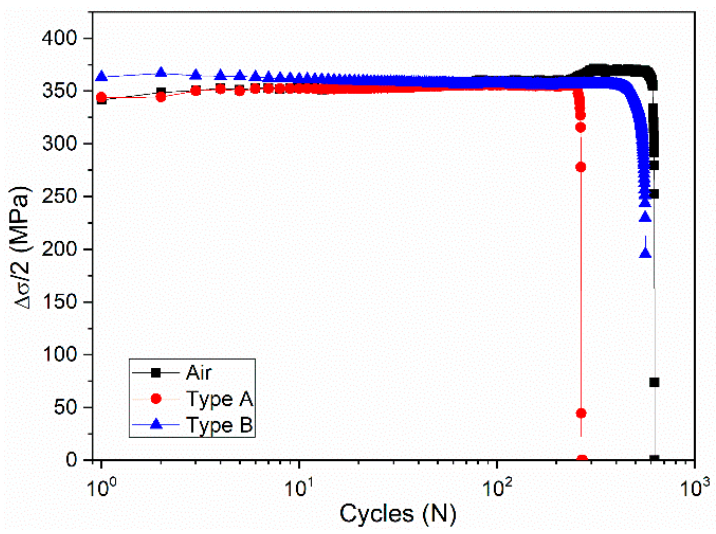

(c)

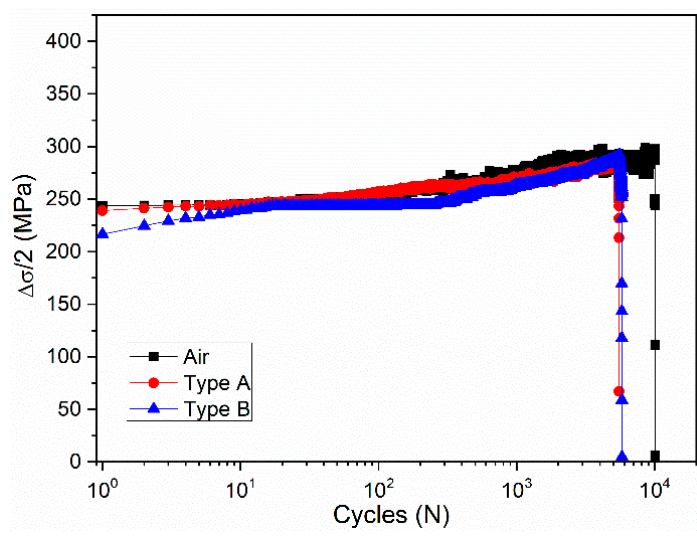

(b)

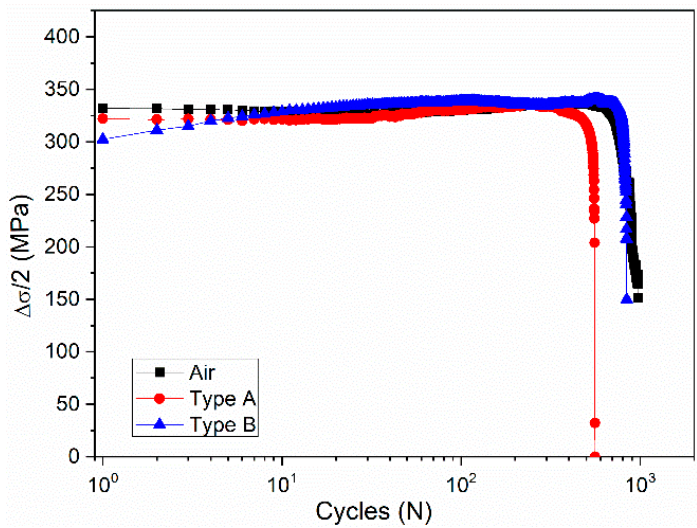

(d)

Figure 4. Cyclic stress response of alloyed steel in different environments $(\mathbf{a}) \pm 0.2 \%,(\mathbf{b}) \pm 0.3 \%,(\mathbf{c}) \pm 0.4 \%$, and $(\mathbf{d}) \pm 0.5 \%$.

Table 5. Fatigue life of specimens in the three environments (cycles).

\begin{tabular}{cccc}
\hline Strain Amplitudes & Air & Mixed Alkali Metal Chloride Salt & Mixed Sulfate Salt \\
\hline $\pm 0.5 \%$ & $627 \pm 33$ & $271 \pm 15$ & $562 \pm 22$ \\
$\pm 0.4 \%$ & $978 \pm 46$ & $559 \pm 21$ & $840 \pm 39$ \\
$\pm 0.3 \%$ & $2444 \pm 128$ & $713 \pm 37$ & $951 \pm 47$ \\
$\pm 0.2 \%$ & $10,053 \pm 484$ & $5524 \pm 278$ & $5778 \pm 282$ \\
\hline
\end{tabular}

In low-cycle fatigue tests, the plastic fatigue strain is relatively high, therefore the life-stress curve $(\mathrm{N}-\mathrm{S})$ cannot be used to describe the fatigue property of the material, and the strain fatigue curve is applied. Coffin and Manson proposed a fatigue life description method in which plastic strain amplitude was taken as a key parameter. The formula is given below:

$$
\Delta \varepsilon_{\mathrm{p}} / 2=\varepsilon_{\mathrm{f}}^{\prime}\left(2 N_{\mathrm{f}}\right)^{\mathcal{C}}
$$

where $\Delta \varepsilon_{\mathrm{p}} / 2$ is the plastic strain, $\varepsilon_{\mathrm{f}}^{\prime}$ is the fatigue ductility coefficient, and $c$ is the fatigue ductility exponent. According to Equation (2), the plastic strain fatigue life of three different steel samples is fitted by using the logarithmically processed Coffin-Manson relationship, as shown in Figure 5. It can be clearly seen that there is a linear relationship between the plastic deformation and the service life, in both air and mixed salt environments. The $c$ value is the slope of the fitting line, and the value $\varepsilon_{\mathrm{f}}^{\prime}$ is the intercept of the line on the longitudinal axis. After fitting, $\varepsilon_{\mathrm{f}}^{\prime}$ and $c$ values are obtained as 
listed in Table 6 . The fatigue ductility coefficient $\varepsilon_{\mathrm{f}}^{\prime}$ represents the fatigue resistance of materials, with a higher value of $\varepsilon_{\mathrm{f}}^{\prime}$ indicating a better fatigue resistance of materials. Additionally, according to the Coffin-Manson equation, the lower the absolute value of fatigue ductility index $c$, the longer the fatigue life. The values of fatigue ductility coefficient and fatigue ductility exponent obtained by the data fitting, show that the fatigue resistance of $12 \mathrm{Cr} 1 \mathrm{MoV}$ steel in two mixed salt environments are lower than that of an air environment.

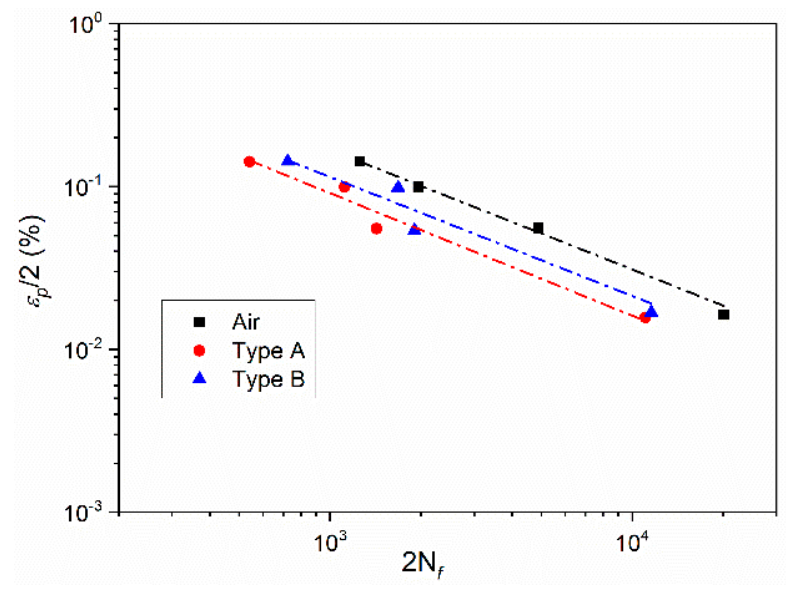

Figure 5. Relationship between plastic deformation and fatigue life of steel tested in different environments.

Table 6. Low-cycle fatigue characteristics parameters $\varepsilon_{\mathrm{f}}^{\prime}$ and $c$.

\begin{tabular}{cccc}
\hline Parameter & Air & Mixed Chloride Salt & Mixed Sulfate Salt \\
\hline$\varepsilon_{f}^{\prime}$ & 26.72 & 16.43 & 17.76 \\
$\mathcal{c}$ & -0.73413 & -0.75219 & -0.73448 \\
\hline
\end{tabular}

\subsection{Fracture Surface Observation}

Figure 6 shows the fatigue fracture morphology of the alloyed steel in different environments with the total strain amplitude of $+0.2 \%$ and $+0.5 \%$ respectively. All fracture surfaces can be clearly divided into either a fatigue crack initiation zone, a fatigue crack propagation zone, or an instantaneous fracture zone, which are marked by A, B, and C in figures respectively. It can be seen that in region $\mathrm{A}$, there are many crack sources located near the surface. Additionally, the number of crack sources is the least in the air environment (Figure $6 a, b$ ), and the number of crack sources is the most in the mixed alkali metal chloride environment (Figure $6 c, d$ ). This indicates that under a mixed salt environment, cracks are easier to form due to the combined action of corrosion and cyclic stress. In the same environment, the higher the total strain amplitude, the more the crack sources. In the fatigue crack propagation area (B zone), there are obvious cowrie patterns, especially under low load conditions (Figure 6b,d,f). These cowrie patterns look like a group of arcs centered on the fatigue source, with the concave side pointing to the fatigue source area, and the convex side pointing to the direction of crack propagation. In places near the fatigue source, the crack propagation is slow and the cowrie patterns are dense. In places far away from the fatigue source area, the cowrie patterns are sparse and the fatigue crack propagation is fast. Under the same conditions, the higher the total strain amplitude, the smaller the fatigue crack growth zone and the less cowrie patterns. With an increase of loading cycles, the cracks increase continuously. When the critical length is reached, the stress intensity factor is higher than the fracture toughness of the material, and the cracks expand rapidly, leading to an instantaneous fracture. Furthermore, it can be seen that shear lips exists in the instantaneous fracture zone, and the shear lip surface is at a certain angle with the loading direction, indicating that the instantaneous fracture is mainly caused by shear stress. 


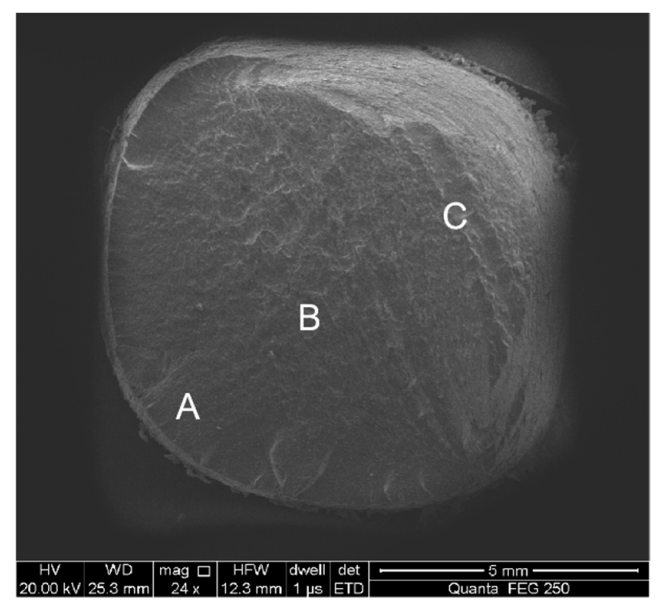

(a)

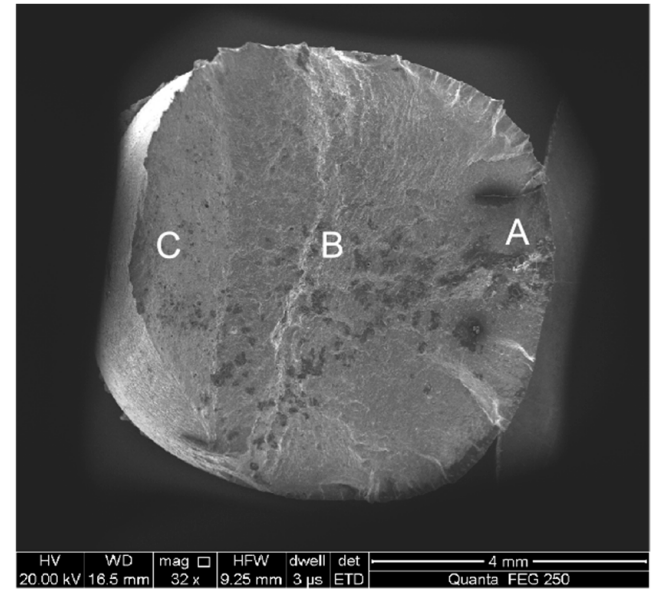

(c)

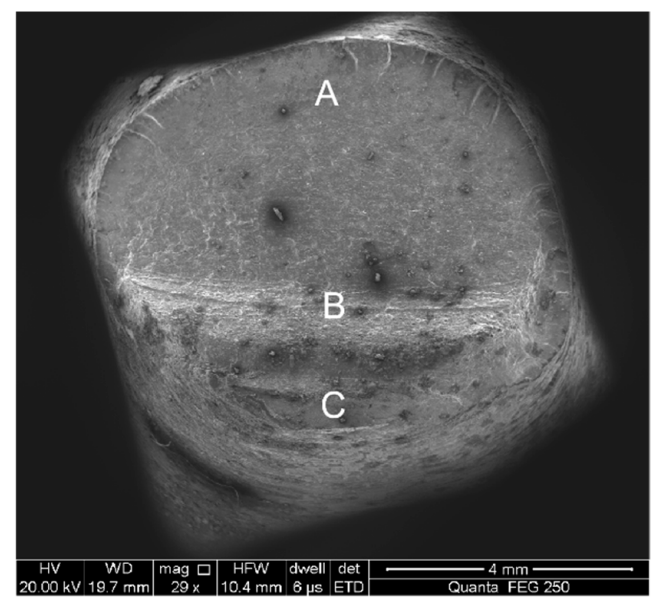

(e)

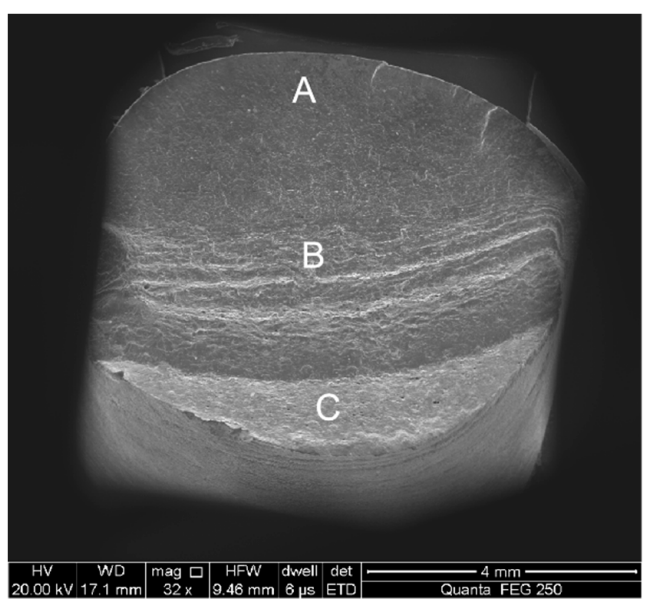

(b)

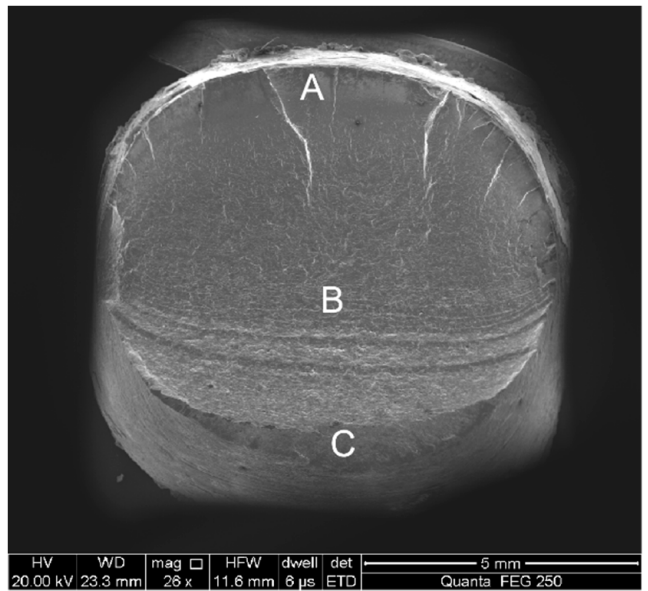

(d)

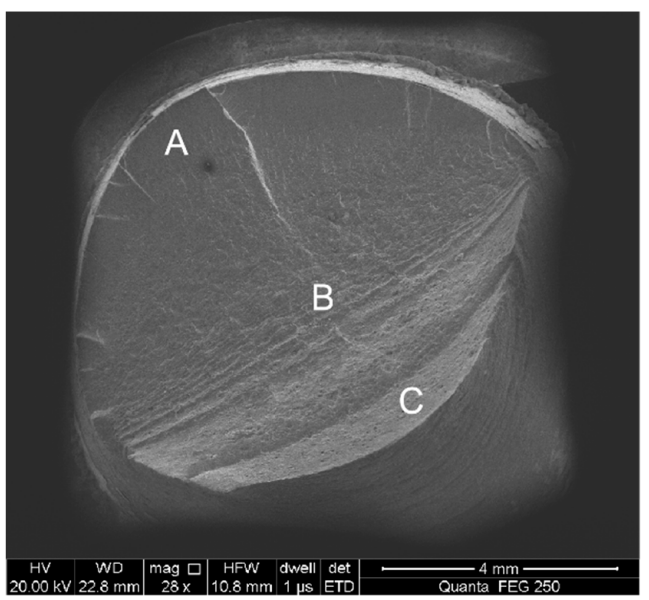

(f)

Figure 6. Overview of the fatigue fracture surface (a) $\pm 0.5 \%$ (air), (b) $\pm 0.2 \%$ (air), (c) $\pm 0.5 \%$ (mixed chloride salt), (d) $\pm 0.2 \%$ (mixed chloride salt), (e) $\pm 0.5 \%$ (mixed sulfate salt), and (f) $\pm 0.2 \%$ (mixed sulfate salt).

Figure 7 shows the detailed morphology of the fatigue crack propagation region. It can be seen that the spacing distance between fatigue striations increases with an increase of strain amplitude. This is because the higher the strain amplitude is, the faster the crack propagation is, subsequently resulting in a shortening of the macroscopic fatigue life. The crack growth region are not as flat as the crack nucleation area, instead the surface is rough and there are many parallel striations on it. 
During this stage, the stress peaks and valleys are relatively stable, and the cracks propagate at a certain rate. Usually the area of the crack propagation region is very large, which consumes most of the fatigue life of the specimens. When comparing the morphology of crack propagation area between an air environment and a mixed chloride salt environment under the same strain amplitude, it can be seen that the spacing distance of fatigue striation in a mixed chloride salt environment is larger than that in an air environment, and that the depth of cracks in the mixed chloride salt environment are deeper, as shown in Figure $7 \mathrm{a}-\mathrm{d}$. This result indicates that the crack growth rate in a mixed chloride salt environment is greater than that in an air environment. The observation of fracture surface shows that a mixed alkali metal chloride environment can be harmful to the fatigue crack resistance of this alloy. Figure 7e,f are images of the fatigue crack propagation region of alloyed steel in a mixed sulfate environment. Its characteristics lie between the air environment and the mixed alkali metal salt environment.

Figure 8 is the typical dimple morphology of the instantaneous fracture region. It can be seen that the surface of the instantaneous fracture zone is rough, and there are many holes and voids with some inclusions. When the interface of inclusions is plastically deformed, it is easy to cause stress concentration, and then cracks are generated and propagate continuously. Subsequently, the matrix between the inclusions forms an "internal plastic neck", which is torn or sheared when the internal plastic neck reaches a certain extent, thus connecting the voids. Finally, forming the observed dimple fracture morphology.

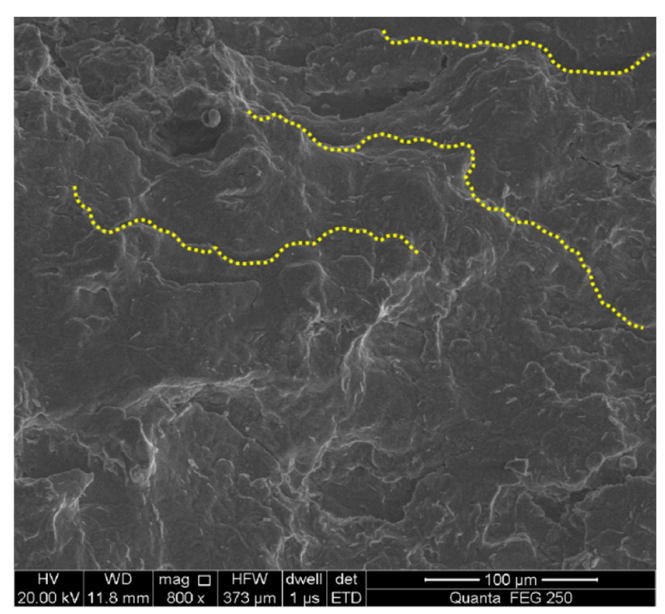

(a)

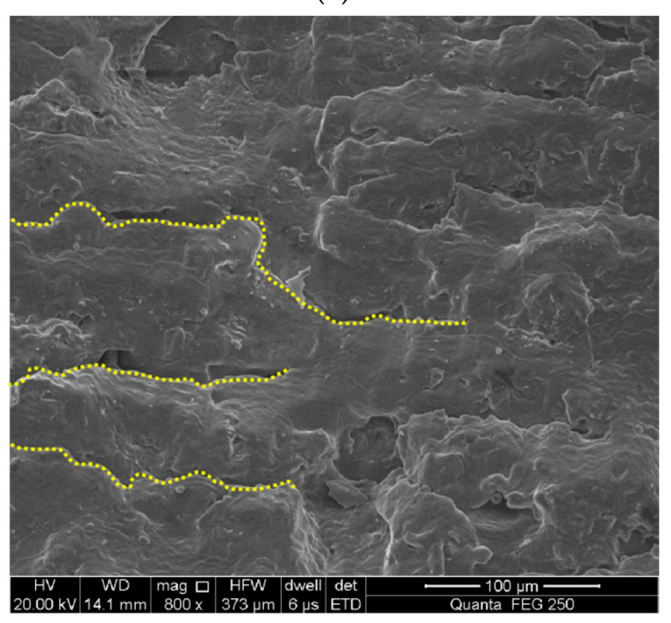

(c)

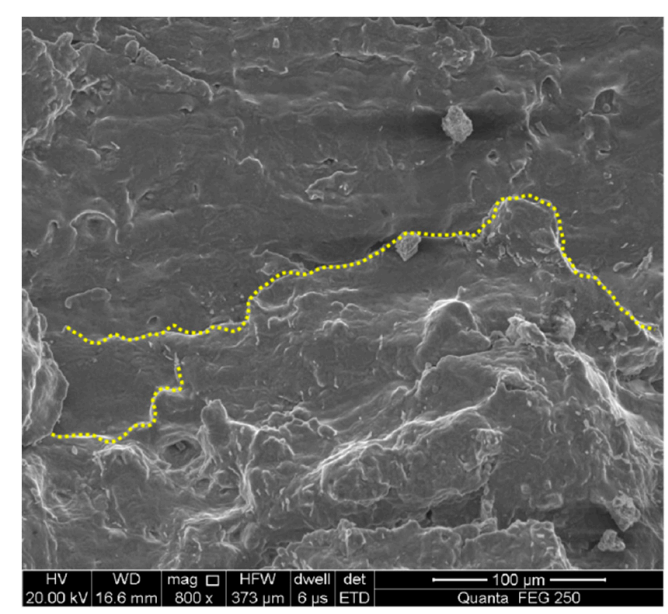

(b)

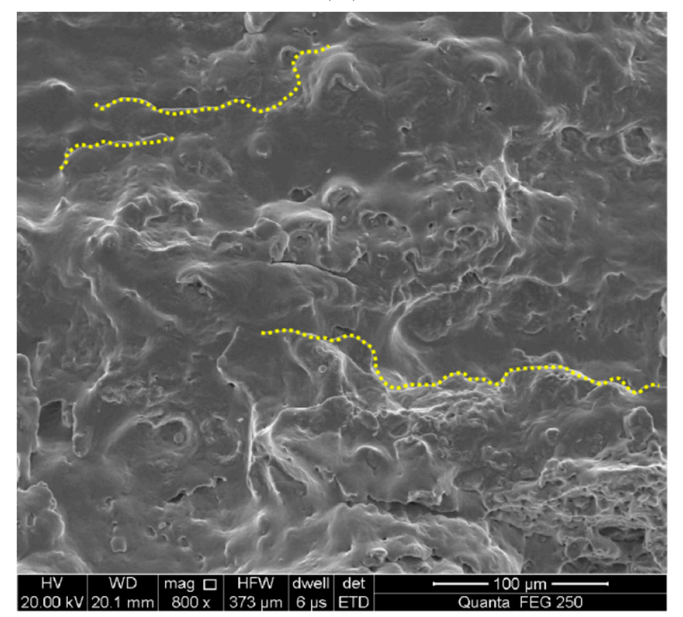

(d)

Figure 7. Cont. 


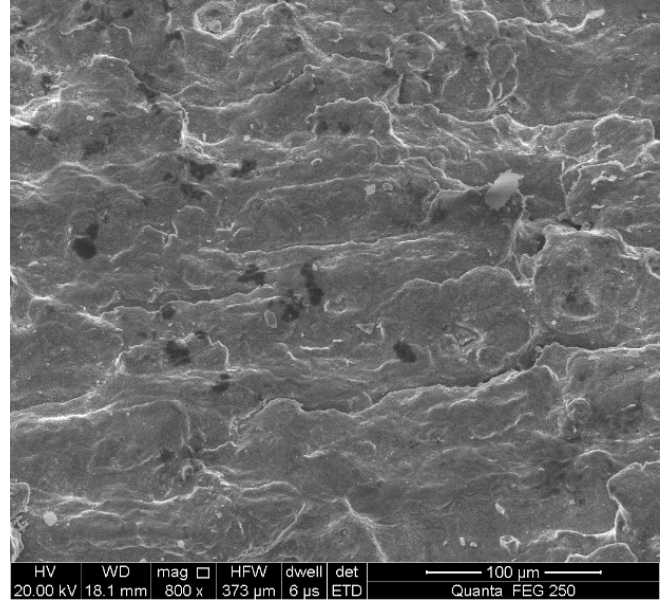

(e)

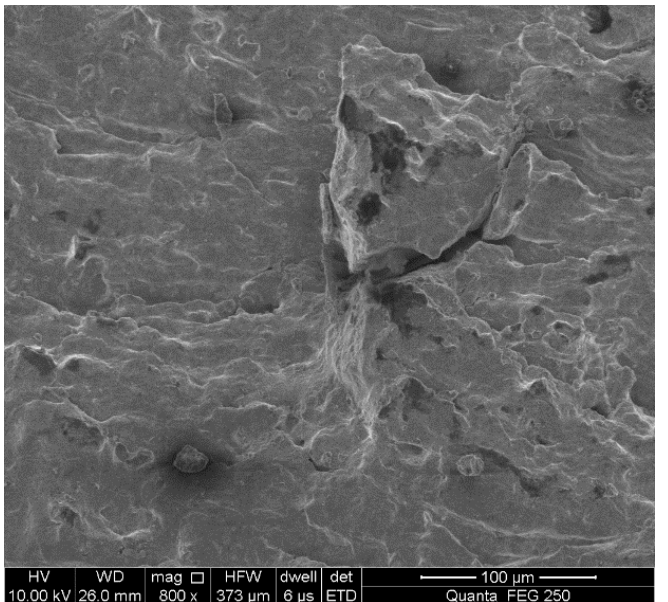

(f)

Figure 7. The fatigue crack propagation region (a) $\pm 0.5 \%$ (air), (b) $\pm 0.2 \%$ (air), (c) $\pm 0.5 \%$ (mixed chloride salt), (d) $\pm 0.2 \%$ (mixed chloride salt), (e) $\pm 0.5 \%$ (mixed sulfate salt), and (f) $\pm 0.2 \%$ (mixed sulfate salt).

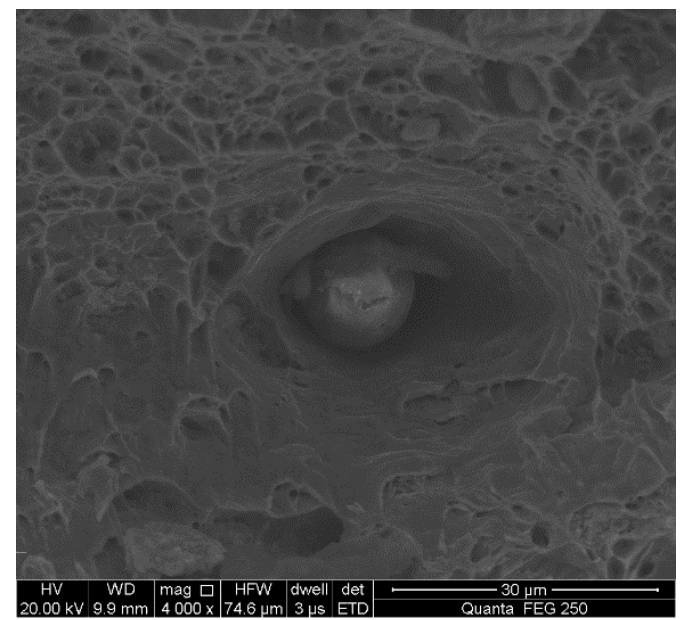

(a)

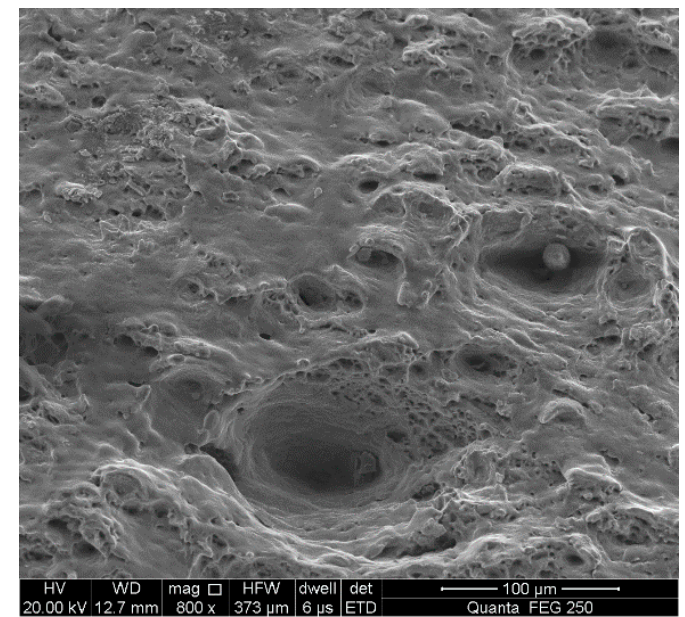

(b)

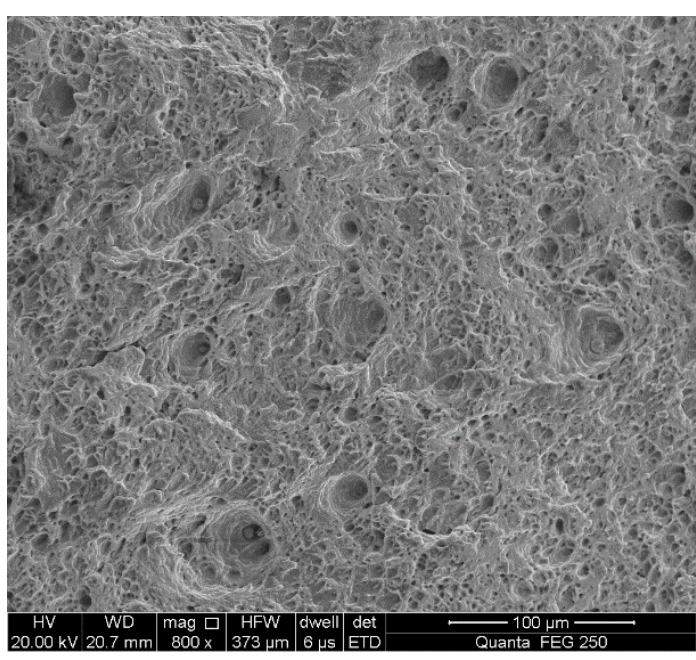

(c)

Figure 8. The fatigue fracture region of the alloy with strain amplitude of $\pm 0.5 \%$ (a) air, (b) mixed chloride salt, and (c) mixed sulfate salt. 
From the above analysis, it can be concluded that the surface and matrix of $12 \mathrm{Cr} 1 \mathrm{MoV}$ steel will be corroded seriously under a high temperature mixed molten chloride environment. With the increase of $\mathrm{KCl}$ content in alkali metal molten salt, the structure of corrosion products on the surface of $12 \mathrm{Cr} 1 \mathrm{MoV}$ steel will change from round granular to flocculent state. The corrosion rate and thickness of corrosion products increase obviously. The corrosion mechanism of test steel in molten salt is the activation and oxidation behavior of chlorine element. The corrosion products of a section are mostly in porous distribution, and the pore size is larger when $\mathrm{Cl}$ element content is higher. The thickness of the corrosion inner layer increases further with an increase of temperature. When corrosion reaction continues, it is easy to change the material quality from weight gain to weight loss by separating some corrosion products from matrix. Under the action of high temperature thermal stress, stress concentration easily occurs near the hole. This results in the initiation and instability propagation of corrosive cracks, further affecting the strength and properties of materials. In a sulfate environment, such corrosion rate is lower, therefore in a fatigue test we can observe that the fatigue property of the samples in chloride environment is the worst.

\section{Conclusions}

The corrosion fatigue properties of $12 \mathrm{Cr} 1 \mathrm{MoV}$ steel under different amplitudes and different environments were studied. The following conclusions can be drawn:

1. The effect of total strain amplitude on the cyclic stress response of the alloy is approximately the same under three different deformation conditions. For all samples, with an increase of total strain amplitude, the cyclic stress values of alloyed steel increased and the fatigue life decreased significantly.

2. With the increase of the cyclic number, all of the samples presented an increment of the cyclic stress, especially at the strain amplitudes of $\pm 0.3 \%$ and $\pm 0.2 \%$. The alloyed steel mainly exhibited cyclic hardening during the loading.

3. The fatigue properties of samples in an air environment are the best, which is most obvious when the total strain amplitude is $\pm 0.3 \%$. The fatigue life of samples in a mixed alkali metal salts is the shortest.

4. Total strain amplitudes and loading environments have great influence on the fatigue fracture morphology of the alloyed steel.

Author Contributions: Data curation, J.B.; investigation, G.W.; methodology, K.L.; writing—original draft, J.H.; writing-review and editing, C.L.

Funding: This research was funded by National Natural Science Foundation of China, grant number 51275058 .

Conflicts of Interest: The authors declare no conflict of interest.

\section{References}

1. Zhang, H.; Zhang, F.; Su, W.; Jiang, Y.; Li, Y. Research and evaluation of T91 superheater material for high temperature corrosion in biomass power plants. Anti-Corros. Methods Mater. 2015, 62, 133-135. [CrossRef]

2. He, J.; Xiong, W.; Zhang, W.; Li, W.; Long, K. Study on the high temperature corrosion behaivor of superheater steels of biomass fired boiler in molten alkali salts' mixtures. Adv. Mech. Eng. 2016, 8. [CrossRef]

3. Retschitzegger, S.; Gruber, T.; Brunner, T.; Obernberger, I. Short term online corrosion measurements in biomass fired boilers. Part 2: Investigation of the corrosion behaivor of three selected superheater steels for two biomass fuels. Fuel Process. Technol. 2016, 142, 59-70. [CrossRef]

4. He, J.; Xiong, W. Effect of high temperature hot corrosion on the compression ceep behabvior of $12 \mathrm{Cr} 1 \mathrm{MoV}$ alloys. High Temp. Mater. Process. 2017, 36, 1011-1023. [CrossRef]

5. Zhu, M.L.; Xuan, F.Z.; Chen, J. Influence of microstructure and microdefects on long term fatigue behavior of a Cr-Mo-V steel. Mater. Sci. Eng. A 2012, 546, 90-96. [CrossRef]

6. Zhu, Z.; Jiao, X.; Tang, X.; Lu, H. Effect of $\mathrm{SO}_{4}{ }^{2-}$ concentration on corrosion behavior of carbon steel. Anti-Corros. Methods Mater. 2015, 62, 322-326. [CrossRef] 
7. Chauhan, A.; Hoffmann, J.; Litvinov, D.; Aktaa, J. Hight-temperatuer low cycle fatigue behavior of a 9Cr-ODS steel: Part 2-hold time influence, microstructural evolution and damage characteristics. Mater. Sci. Eng. A 2018, 730, 197-206. [CrossRef]

8. Xiong, S.; Zhu, Z.; Jing, L. Influence of Cl-ions on the pitting corrosion of bolier water wall tube and its principle. Anti-Corros. Methods Mater. 2012, 59, 3-9. [CrossRef]

9. Liu, S.; Liu, Z.; Wang, Y.; Tang, J. A comparative study on the high temperature corrosion of TP347H stainless steel, C22 alloy and laser-cladding C22 coating in molten chloride salts. Corros. Sci. 2014, 83, 396. [CrossRef]

10. Zhang, T.B.; Dong, R.F.; Rui, H.; Kou, H.C.; Li, J.S. Hot corrosion characteristics of Ni-20Cr-18W superalloy in molten salt. Trans. Nonferr. Met. Soc. China 2015, 25, 3840-3846. [CrossRef]

11. Tsaur, C.C.; Rock, J.C.; Wang, C.J.; Su, Y.H. The hot corrosion of 310 stainless steel with precoated $\mathrm{NaCl}_{2} / \mathrm{Na}_{2} \mathrm{SO}_{4}$ mixtures at $750{ }^{\circ} \mathrm{C}$. Mater. Chem. Phys. 2005, 89, 445-453. [CrossRef]

12. Halford, G.; Hirschberg, M.; Manson, S. Creep-Fatigue Analysis by Strain Range Partitioning; NASA Lewis Research Center: Cleveland, OH, USA, 1971.

13. Zenr, C.; Holloman, J. Effect of strain rate upon the plastic flow of steel. J. Appl. Phys. 1944, 15, 22. [CrossRef]

14. Seifert, T.; Riedel, H. Mechanism-based thermomechanical fatigue life prediction of cast iron. Part 1: Models. Int. J. Fatigue 2010, 32, 1358-1367. [CrossRef]

(C) 2019 by the authors. Licensee MDPI, Basel, Switzerland. This article is an open access article distributed under the terms and conditions of the Creative Commons Attribution (CC BY) license (http://creativecommons.org/licenses/by/4.0/). 